\title{
Letters
}

Website: bmj.com

Email: letters@bmj.com

\section{The quality of systematic reviews}

\section{Review is biased}

EDITOR-In discussing meta-analyses in the treatment of asthma, Jadad et al state that most reviews published in peer reviewed journals or funded by industry have serious methodological flaws. ${ }^{1}$ This summary is misleading and could have been put more succinctly as, "most reviews published in peer reviewed journals have serious methodological flaws," since the industry reviews in their paper were a (similar) subset of the published papers.

Jadad et al are, however, right in drawing attention to the inherent bias in their Cochrane approved quality index. Cochrane reviews are excellent in many respects but grossly deficient in at least one-namely, the reliance on software, RevMan, that is incapable of satisfying an essential and elementary requirement placed by drug regulators on sponsors, that "the particular model chosen should reflect the state of medical knowledge about the variables to be analysed as well as the statistical design of the trial." RevMan cannot deal appropriately with covariates nor with multicentre, cluster randomised, minimised, or crossover trials. It is thus a suitable tool

\section{Advice to authors}

We prefer to receive all responses electronically, sent either directly to our website or to the editorial office as email or on a disk. Processing your letter will be delayed unless it arrives in an electronic form.

We are now posting all direct submissions to our website within 24 hours of receipt and our intention is to post all other electronic submissions there as well. All responses will be eligible for publication in the paper journal.

Responses should be under 400 words and relate to articles published in the preceding month. They should include $\leqslant 5$ references, in the Vancouver style, including one to the BMJ article to which they relate. We welcome illustrations.

Please supply each author's current appointment and full address, and a phone or fax number or email address for the corresponding author. We ask authors to declare any competing interest. Please send a stamped addressed envelope if you would like to know whether your letter has been accepted or rejected.

Letters will be edited and may be shortened.

bmj.com

letters@bmj.com for single centre, randomised, parallel group trials in which no covariates are measured: a type of trial that is rather rare in my experience. On the other hand, the pharmaceutical industry has long employed doctors and statisticians capable of dealing with the complications of real clinical trials. For a good illustration, see the paper by Richardson and Bablok, ${ }^{3}$ which Jadad et al did not include.

The biased and one sided review by Jadad et al cannot be taken as showing the superiority of Cochrane reviews to pharmaceutical industry reviews.

Stephen Senn professor of pharmaceutical and health statistics

University College London, London WC1E 6BT stephens@public-health.ucl.ac.uk

Competing interests: Professor Senn is a consultant to the pharmaceutical industry.

1 Jadad AR, Moher M, Browman GP, Booker L, Sigouin C, Fuentes M, et al. Systematic reviews and meta-analyses on Fuentes M, et al. Systematic reviews and meta-analyses on
treatment of asthma: critical evaluation. BMJ treatment of asthma: cric

2 International Conference on Harmonisation Statistical Principles for clinical trials. Statist Med 1999;18:1905-42.

3 Richardson W, Bablok B. Clinical experience with formoterol in adults. In: Holgate ST, ed. Formoterol: fast and long-lasting bronchodilation. London: Royal Society of Medicine Services, 1992:23-37.

\section{High quality reporting of both} randomised trials and systematic reviews should be priority

EDITOR-Senn ${ }^{1}$ [previous letter] is critical of the conclusion of Jadad et al in their critical evaluation that "most reviews published in peer reviewed journals or funded by industry have serious methodological flaws." We agree that this remark was overly strong. Firstly, Jadad et al considered the reporting quality as well as the quality of the review, and we would expect (although regret) poorer reporting in journals, where limitations on space might prevent the publication of key information. This does not invalidate the comparison, however, as it is important to know how well research is reported in medical journals. Secondly, although the contrast between Cochrane and journal reviews was clear, only six of the 38 reviews in journals were industry sponsored, too few to make a safe generalisation.

We do not agree, however, with Senn's description of the article of Jadad et al as "biased and one-sided." Jadad et al used a quality score to assess systematic reviews in asthma published in medical journals and in the Cochrane Library. This scoring system accords well with the recently published QUOROM Statement. Also, it should be of concern that the authors of fewer than half of the 38 reviews published in journals reported factors such as how they searched the literature, the criteria they used to determine which studies to include in their systematic review, or the statistical methods used to combine the data.

Senn's letter also discusses the Cochrane software RevMan, a topic not addressed by Jadad et al. Unfortunately, he gives the impression that Cochrane reviewers are allowed to use only RevMan in their analysis-this is not true. Also, and crucially, he does not recognise that nearly all Cochrane reviews are performed using summary statistics from published (and sometimes unpublished) papers, whereas reviews performed within the industry would have access to individual patient data. It is entirely appropriate to take covariate information into account in the latter, but it is usual (not just in the Cochrane Collaboration) to perform meta-analysis of the former using unadjusted data.

Lastly, there are indeed problems associated with incorporating crossover and cluster trials into meta-analyses, but these are largely resulting from inadequate reporting of these types of trial. We should seek to correct these inadequacies and insist on high quality reporting of both randomised trials ${ }^{4}$ and systematic reviews, ${ }^{3}$ and this was the concern of Jadad et al. ${ }^{2}$

Douglas G Altman professor of statistics in medicine altman@icrf.icnet.uk

Jonathan J Deeks senior medical statistician Centre for Statistics in Medicine, Institute of Health Sciences, Headington, Oxford OX3 7LF

Mike Clarke associate director (research) UK Cochrane Centre, Oxford OX2 7LG

Christopher Cates general practitioner

Bushey, Hertfordshire WD2 2NN

Competing interests: All the authors have substantial involvement in the work of the Cochrane Collaboration.

1 Senn S. Biased review. bmj.com 2000;320 (bmj.com/cgi/ eletters/320/7234/537\#EL2; accessed 26 June).

2 Jadad AR, Moher M, Browman GP, Booker L, Sigouin C, Fuentes M, et al. Systematic reviews and meta-analyses on treatment of asthma: critical evaluation. BMJ 2000·320:537-40. (26 February)

3 Moher D, Cook DJ, Eastwood S, Olkin I, Rennie D, Stroup $\mathrm{DF}$, for the QUOROM Group. Improving the quality of reports of meta-analyses of randomised controlled trials: the QUOROM statement. Lancet 1999;354:1896-900.

4 Begg C, Cho M, Eastwood S, Horton R, Moher D, Olkin I, et al. Improving the quality of reporting of randomized controlled trials: the CONSORT statement. JAMA 1996;276:637-9. 


\section{Criticism is unjustified}

EDITOR-In their systematic review Jadad et al have critically evaluated systematic reviews and meta-analyses of the treatment of asthma and judged 40/50 papers as having serious or extensive flaws that limit their value to guide decisions.

The Oxman and Guyatt scale used as a criterion is well recognised as useful in assessing the quality of systematic reviews and meta-analyses where extensive selection, by the authors, of studies from the worldwide literature is made. ${ }^{2}$ The reviews judged by Jadad et al as most rigorous all had extensive selection processes-for example, the Cochrane review of Gibson et al reviewed only 11 studies from a possible 53 selected from 156 source hits. ${ }^{3}$ In cases such as this it is essential that authors state clearly and in detail the methods they used to justify their extremely small sample from the total population. The Oxman scale is particularly sensitive to reviews with selection bias and rightly condemns them as variously flawed.

One of the papers criticised did not involve any selection at all. ${ }^{4}$ The paper clearly stated that all the controlled worldwide studies with data available and meeting the given criteria were used. The applicability of the Oxman scale to this particular meta-analysis may therefore be called into question.

Jadad has subsequently provided us with the individual components of the assessment, which showed that our paper had serious or extensive flaws. This was based on us not stating our reasons for believing that all the studies used were valid. We agree that some readers may not have understood the validity implications of the word "controlled" and accept that a more explicit statement was needed. The facts are that all 14 studies included in the analysis out of a total of 14 studies completed worldwide at the time point stated were standard randomised drug comparisons. They were all conducted according to European standards of good clinical practice and are valid according to the criteria underlying the Oxman index.

All Cochrane reviews, including those studies described by Jadad et al as rigorous, contact authors of the reviewed papers before publication to clarify matters of fact. It is unfortunate that this omission by Jadad et al to adopt the same procedures has resulted in the science of our paper being inappropriately classified as being severely or extensively flawed on the basis of our failing to detail the validation process.

N C Barnes consultant physician The London Chest Hospital, London E2 9JX

C Hallett consultant statistician

Fast Cycle Sciences Limited, PO Box 221, Epsom KT17 2WF

ch90810@GlaxoWellcome.co.uk

T A J Harris professional relations manager GlaxoWellcome, Uxbridge, Middlesex UB11 1BT

Competing interests: Dr Barnes has received research funding, sponsorship to attend meetings, and lecture fees from GlaxoWellcome; Mr Harris is employed by and Mr Hallett provides consultancy services to GlaxoWellcome.
1 Jadad AR, Moher M, Browman GP, Booker L, Sigouin C, Fuentes M, et al. Systematic reviews and meta-analyses on treatment of asthma: critical evaluation. $B M$ 2000;320:537-40. (26 February.)

2 Oxman AD, Guyatt GH. Validation of an index of the quality of review articles. J Clin Epidemiol 1991;44:1271-78. 3 Gibson PG, Coughlan J, Wilson AJ, Hensley MJ, Abramson M, Bauman A, et al. The effects of limited (information only) patient education programs on the health outcomes of adults with asthma. In: Cochrane Collaboration Cochrane Library. Issue 1 Oxford: Update Software, 2000.

4 Barnes NC, Hallett C, Harris TA. Clinical experience with futicasone proprionate in asthma: a meta-analysit efficasone proprionate in asthma. a meta-analysis of eflicacy and systenic actinty compared with budesonide dose or less. Resp Med 1998;92:95-104.

\section{Cochrane Collaboration should ensure equitable participation in management and policy}

EDITOR-The article by Jadad et al illustrates the success of the Cochrane Collaboration in minimising bias. $^{1}$ The collaboration scrupulously implements the science of data synthesis. We believe that the collaboration should apply the same scrupulous approach to ensure equitable participation in its management and policy. In our experience, men dominate editorial groups, so we examined the evidence to support or refute this initial impression.

We analysed the composition of editorial teams from the Cochrane Library, Issue 2 , 1999, when there were 48 collaborative review groups, with data available on $45 .^{2}$ Each review group generally has one coordinating editor who has overall responsibility for the group, other editors who contribute to policy and content, and coordinators, who are full time employees organising the day to day editorial work.

We found that one quarter of collaborative review groups $(11 / 45)$ had no women editors at all. Ten out of 45 coordinating editors were women $(21 \%)$, and only 61 women were other editors $(24 \%, 61 / 196)$. There were no women editors from developing countries. In contrast, the analysis showed that most coordinators were women $(78 \%$, $37 / 47)$. Although we did not collect data, editors are generally in secure posts, whereas coordinators are usually funded by short term grants, with contracts between three months and two years.

We believe that this imbalance was not intended by people organising review groups but is the result of several related factors. Cochrane contributors usually come from academia or medicine, both of which traditionally discriminate against women. The collaboration depends on individuals making considerable efforts on top of their existing jobs over long periods of time, which will discriminate against women, who are the main carers of children and have less flexibility to work outside office hours. In addition, the collaboration depends heavily on networking in the workplace, which is traditionally a male practice. Our findings raise interesting research questions about whether the predominance of men affects what reviews are done, what outcomes are chosen, and how results are interpreted.

The Cochrane Collaboration steering group has considered these findings. It is currently canvassing the views of collaboration members with respect to adding a prin- ciple concerning equity in relation to sex and other barriers to full participation at all levels. We look forward to explicit methods of how collaborative review groups will address the current inequities.

Carole Wilson research fellow

Department of Sociology, Social Policy and Social Work Studies, University of Liverpool, Liverpool L69 7ZA

Paula Waugh divisional secretar

Paul Garner coordinating editor, Cochrane Infectious Diseases Group

International Health Division, Liverpool School of Tropical Medicine, Liverpool L3 5QA

Competing interests: None declared.

1 Jadad AR, Moher M, Browman GP, Booker L, Sigouin C, Fuentes M, et al. Systematic reviews and meta-analyses on Fuentes M, et al. Systematic reviews and meta-analyses on treatment of

2 Waugh P, Wilson C, Garner P. Gender bias within the Cochrane Collaboration: are we guilty of discrimination against women? Rome: VII Cochrane Colloquium [poster], October 1999.

\section{Authors' reply}

EDITOR-This issue of the BMJ contains four letters in response to our recent critical evaluation of systematic reviews and metaanalyses on the treatment of asthma. ${ }^{1}$

Senn used most of the space available for his letter to address the limitations of RevMan software, an issue not related to our article. His assessment of our report as "biased" and "one sided" was based entirely on one sentence in the abstract and on our decision to use the Oxman and Guyatt index to assess the quality of the reviews. We agree that the first sentence of the conclusion of our abstract could be misleading if it were taken out of context. This sentence, which referred to the articles included in the review, reflected our findings accurately: all six reviews associated with industry had low quality scores. Our decision to use the Oxman and Guyatt index was based on the fact that it is still the only validated tool to appraise review articles. This index was first published in a medical journal ${ }^{2}$ and, as Altman et al pointed out, includes questions that are likely to be part of any instrument to assess the quality of review articles. ${ }^{3}$ Lack of description of the literature search, selection criteria, and the methods used to synthesise the data are regarded as serious deficiencies, in any review article, by most standards.

Barnes et al provided reasons for the low scores given to their article. They accept that they should have provided a more explicit statement on the validity of the "controlled" trials included in their review. A mere description of a study as a randomised controlled trial does not guarantee its validity. ${ }^{5}$ They did not feel the need to describe their literature search process because they stated that they had included all trials available, worldwide. This strong claim could only be verified by following a detailed description of the process to locate the studies. Replicability should one of the essential features of a rigorous review.

The letter by Wilson et al makes two important, albeit unrelated, points: that there is sex bias within the Cochrane 
Collaboration and that it may have an effect on Cochrane reviews. We were glad to learn that the collaboration is acting upon their findings. Similar efforts may be required to ensure adequate balance and equity of the sexes in the generation of new health related knowledge throughout the world.

Alejandro R Jadad professor

Department of Clinical Epidemiology and

Biostatistics, McMaster University, 1200 Main Street

West, Hamilton, Canada L8N $3 Z 5$

Michael Moher Royal College of General Practitioners research training fellow

Institute of Health Sciences, University of Oxford,

Old Road, Headington, Oxford OX3 7LF

George $\mathbf{P}$ Browman professor

Lynda Booker research assistant

Department of Clinical Epidemiology and

Biostatistics

Christopher Sigouin doctoral student

Department of Clinical Epidemiology and

Biostatistics, McMaster University, Hamilton,

Canada, L8N 375

Mario Fuentes research assistant

Robert Stevens research assistant

Foresight Consultants, Dundas, Ontario, Canada

L9H 2R5

Competing interests: Professor Jadad is codirector of the Canadian Cochrane Network and Centre.

1 Jadad AR, Moher M, Browman GP, Booker L, Sigouin C, Fuentes M, et al. Systematic reviews and meta-analyses on the treatment of asthma: a critical evaluation. $B M J$ 2000;320:537-40.

2 Jadad AR, McQuay HJ. Meta-analysis to evaluate analgesic interventions: a systematic review of their methodology. Clin Epidemiol 1996;49:235-43.

3 Moher M, Cook DJ, Eastwood S, Olkin I, Rennie R, Stroup $\mathrm{DF}$, for the QUOROM Group. Improving the quality of reports of meta-analyses of randomised controlled trials: he QUOROM statement. Lancet 2000;354:1896-900 (www.thelancet.com/newlancet/eprint/2/ (accessed 19 May 2000).)

4 Shea B, Dubé C, Moher D. Assessing the quality of reports of systematic reviews and meta-analyses: a systematic review of checklists and scales. Proceedings of the VII Cochrane Colloquium, 1999.

5 CONSORT statement. www.consort-statement.org/

(accessed 19 May 2000).

\section{Paramedics should delay giving aspirin to patients with stroke}

EDITOR-The Royal College of Physicians has produced clinical guidelines for stroke. ${ }^{1}$ These include recommendations for the treatment of acute stroke. The first recommendation is that $300 \mathrm{mg}$ aspirin should be given as soon as possible after the onset of stroke symptoms (if a diagnosis of haemorrhage is considered unlikely). This recommendation is graded $\mathrm{A}$, indicating that the evidence is strong. Because of this the Oxfordshire ambulance service considered having paramedics treat patients with aspirin but consulted widely with clinicians to gain their support.

We found that the recommendation in the guidelines might not be applicable before patients reach hospital. Aspirin has been shown to reduce the risk of early recurrent ischaemic stroke when given within 48 hours of acute stroke. ${ }^{23}$ However, any benefit in reducing the severity of the acute stroke seems to be small, and there is no evidence that overall benefit would be reduced by delaying the administration of aspirin by an hour or so. ${ }^{2}$ Paramedics have been trained to administer aspirin safely in acute myocardial infarction, ${ }^{4}$ but in cases of acute stroke there are potential dangers in using aspirin before the patient reaches hospital.

Firstly, the number of cases was small and the confidence intervals were wide in two studies that found that there was no evidence of harm in patients with acute stroke who had been randomly allocated to receive aspirin before having computed tomography of the brain and who were subsequently found to have had an intracerebral haemorrhage. ${ }^{2{ }^{3}}$ Thus, since it is difficult to exclude intracerebral haemorrhage on clinical grounds there remains a potential risk of harm occurring with the inadvertent administration of aspirin to patients with intracerebral haemorrhage.

Secondly, the ability to swallow safely is commonly impaired in the acute phase of stroke. Given the potential difficulties of training paramedics to assess swallowing, aspirin would have to be administered rectally in order to avoid the risk of aspiration.

We therefore decided that if there is no evidence that a short delay in administering aspirin reduces its efficacy in acute stroke and since there is some potential for harm, the indignity of rectal administration by paramedics could not be justified. We wonder what other ambulance services are doing and whether future recommendations should take into account the prehospital phase of treatment.

Michael Ward medical director Oxfordshire Ambulance NHS Trust, Ambulance Headquarters, Oxford $\mathrm{OX} 37 \mathrm{LH}$

michael.ward@anaesthetics.oxford.ac.uk

Peter M Rothwell MRC senior clinical fellow Department of Clinical Neurology, Radcliffe Infirmary, Oxford OX2 6HE

peter.rothwell@clneuro.ox.ac.uk

1 Intercollegiate Working Party for Stroke. National clinical guidelines for stroke. London: Royal College of Physicians, 2000

2 International Stroke Trial Collaborative Group. The international stroke trial (IST): a randomised trial of aspirin, heparin, both or neither among 19435 patients with acute heparin, both or neither among 19 435 patient

3 CAST (Chinese Acute Stroke Trial) Collaborative Group. 3 CAST (Chinese Acute Stroke Trial) Collaborative Group.
CAST:randomised placebo controlled trial of early aspirin use in 20000 patients with acute ischaemic stroke. Lancet use in 20000 patien

1997;349:1641-9

4 Funk D, Groat C, Verdile VP. Education of paramedic

regarding aspirin use. Prehospital Emerg Care 2000;4:62-4.

\section{Acute ischaemic stroke}

Thrombolysis for acute ischaemic stroke works

EDITOR-We disagree with the thrust of Gubitz and Sandercock's interpretation of the evidence for treatment of acute ischaemic stroke. ${ }^{1}$ The meta-analysis that they quote includes three different thrombolytic agents, different time windows, and different doses. There may be no statistical evidence of heterogeneity of treatment effect, but there are clinical grounds to believe that these factors make for critically important differences.

In the same meta-analysis the more homogeneous data drawn from the three trials that treated patients with intravenous alteplase within three hours of onset are also reported. A major treatment effect is observed, with an odds ratio of 0.55 (95\% confidence interval 0.42 to 0.72 ) in favour of treatment. These patients include those who had early intracerebral haemorrhage. In this 0-3 hour group there is no increased mortality.

The same analysis for the streptokinase trials shows no benefit but is impaired by the small numbers of patients treated within three hours of the onset of symptoms. A similar 3-6 hour analysis for patients treated with alteplase is not available, but the pooled streptokinase and alteplase 3-6 hour results show no benefit, with an odds ratio of 0.93 $(0.78$ to 1.10$)$ in favour of treatment. This result is in keeping with that seen in the alteplase thrombolysis for acute noninterventional therapy in ischemic stroke (ATLANTIS) trial. ${ }^{3}$ Ultimately, it seems likely that the treatment effect in the 3-6 hour time window with alteplase is of lesser magnitude than that seen in the 0-3 hour time window.

Postmarketing experience in North America and Germany, largely from centres that developed experience with thrombolysis in acute ischaemic stroke during clinical trials, has been remarkably positive. Rates of symptomatic haemorrhage and 90 day outcomes have been in line with the published data from the National Institute of Neurological Disorders and Stroke r-TPA stroke (NINDS) study ${ }^{45}$ These results add tremendous weight to the argument that the meta-analysis is biased because of the heterogeneity of trials included. We agree that the treatment needs refining, but intravenous alteplase is undoubtedly efficacious when given within three hours of the onset of stroke using this study's criteria. Stating "we found little evidence on balance between benefits and harms from thrombolysis in acute ischaemic stroke" does little to further the development of the treatment of acute stroke and may stifle emerging enthusiasm for thrombolysis within three hours of the onset of stroke in Britain. Further trials to define the benefit or harm of thrombolysis after three hours will be welcome.

Michael D Hill clinical stroke fellow michael.hill@crha-health.ab.ca

Philip A Barber clinical stroke fellow Andrew M Demchuk assistant professor Alastair M Buchan professor

Department of Clinical Neurosciences, University of Calgary, Stroke Research Office, Foothills Hospital, Calgary, AB T2N 2T9, Canada Competing interests: Drs Hill, Demchuk, and Buchan have received fees for speaking from Hoffman-La Roche Canada, and Dr Barber has received travel assistance from Knoll Pharma.

1 Gubitz G, Sandercock P. Acute ischaemic stroke. BMJ 2000.692-6. (11 March.)

2 Wardlaw JM, del Zoppo G, Yamaguchi T. Thrombolysis for acute ischaemic stroke. In: Cochrane library. Issue 4 Oxford Update Software, 1999: 1-25.

3 Clark WM, Wissman S, Albers GW, Jharmandas JH, Madden KP, Hamilton S for the ATLANTIS Study Investigators. Recombinant tissue-type plasminogen activator (alteplase) for ischemic stroke 3 to 5 hours after symptom onset. The ATLANTIS study: a randomised controlled trial. JAMA 1999;282:2019-26.

4 Albers GW, Bates VE, Clark WM, Bell R, Verro P, Hamilton SA. Intravenous tissue-type plasminogen activator for treatment of acute stroke: the standard treatment with alteplase to reverse stroke (STARS) study JAMA 2000;283:1145-50.

5 Buchan AM, Baber PA, Newcommon NJ, Karbalai HC, veness of t-PA in acute ischemic stroke: outcome relates to appropriateness. Neurology 1999;54:679-84. 
Large trial of effect of reducing blood pressure in acute stroke is being set up

EDITOR-Gubitz and Sandercock review the question of reducing blood pressure in acute stroke, quoting a collaboration and systematic review that we manage. ${ }^{12}$ In addition to pointing out that this question has yet to be tested in a large scale randomised controlled trial, they suggest that lowering blood pressure may be harmful, largely as a result of trials using calcium channel blockers (especially intravenous nimodipine) or $\beta$ adrenoceptor antagonists. It is inappropriate, however, to extrapolate the results from these trials to all antihypertensive agents and suggest that any form of blood pressure lowering may be detrimental.

Firstly, calcium channel blockers and $\beta$ adrenoceptor antagonists may be harmful for class specific reasons-for example, they are both negatively inotropic-while calcium channel blockers may cause arrhythmias and cerebral steal, both of which can reduce cerebral blood flow.

Secondly, trials in acute stroke often use drugs at doses that, while safe in younger, fit, often male adults, may be excessive in sick, frail, older, often female patients with stroke; this criticism can certainly be levelled at some studies of calcium channel blockers. Importantly, it is possible to give antihypertensive agents-for example, angiotensin converting enzyme inhibitors or nitric oxide donors-at doses that cause relatively small reductions in blood pressure $(<15 \%)$ without reducing cerebral perfusion. ${ }^{34}$

Lastly, trials of agents in acute stroke that raised blood pressure (and may, therefore, have increased cerebral blood flow in the absence of cerebral autoregulation) have also been unsuccessful-for example, aptiganel and diaspirin cross linked haemoglobin.

In the absence of definitive trial data, we are planning a large multicentre randomised controlled trial (the efficacy of nitric oxide in stroke trial) to test the question of whether it is safe and efficacious to lower blood pressure with transdermal glyceryl trinitrate during the acute phase of stroke; further information is given at www.nottingham.ac.uk/stroke-medicine/ enossummary.htm.

Philip Bath professor

philip.bath@nottingham.ac.uk

Fiona Bath scientist

Parveen Rashid clinical research fellow

Chris Weaver research nurse

Division of Stroke Medicine, University of Nottingham, City Hospital Campus, Nottingham NG5 $1 \mathrm{~PB}$

Competing interests: None declared.

1 Gubitz G, Sandercock P. Acute ischaemic stroke. BMy 2000;692-6. (11 March.)

2 Blood Pressure in Acute Stroke Collaboration (BASC) Interventions for deliberately altering blood pressure in acute stroke (Cochrane reviews). In: Cochrane library. Oxford: Update Software, 1999.

3 Dyker AG, Grosset DG, Lees K. Perindopril reduces blood pressure but not cerebral blood flow in patients with recent cerebral ischaemic stroke. Stroke 1997-28.580-3.

4 Butterworth RI Cluckie A, Jackson SHD, Buxton-Thoma M, Bath PMW Pathophysiological assessment of nitric M, Bath PMW. Pathophysiological assessment of nitric oxide (given as sodium nitroprusside)
stroke. Cerebrovasc Dis 1998;8:158-65.

\section{Patients in rheumatology clinics need reassurance}

Editor-As rheumatologists, we were delighted to see your issue devoted to chronic disease. Donovan and Blake are to be congratulated on tackling the important issue of reassurance in chronic disease management. ${ }^{1}$ The reassurance seemed, however, directed to the doctors' expectations of the patients' concerns rather than the patients' actual fears. Neither the preliminary interview nor the consultation seemed to define what patients actually worried about.

Fear is a powerful emotion experienced by many people with musculoskeletal disorders. The disabling effects of fear caused to patients by back pain have been clearly identified $^{2}$ and may have important consequences for their behaviour. ${ }^{3}$ A specific questionnaire has therefore been constructed to elucidate the context of patients fears. ${ }^{4}$

Patients' fears can often be ascertained by asking the simple question, "what is it that worries you most about your condition?" In a rheumatological clinic for back pain, 86 consecutive new patients were asked what worried them about their back pain. Only 13 (15\%) denied specific fears; 55 (64\%) admitted to fears about possible future disability (loss of independence or work or both, or being confined to a wheelchair); $18(19 \%)$ were worried about the cause of their pain (cancer, arthritis, degeneration); and 2 (2\%) had other concerns (for example, clicking in the back). ${ }^{5}$ It is not surprising that patients with peripheral joint symptoms are also concerned about potential disability. ${ }^{1}$

The importance of Donovan and Blake's work lies in two areas, both requiring attention in rheumatology training programmes. Firstly, rheumatologists should be able to appreciate patients' fears irrespective of their own preconceptions. Secondly, they would be in a better position to allay fears about future disability if they received better training in disability management. The current specialist training in rheumatology seems deficient in both these areas.

It is illogical to try to offer reassurance in the absence of defining the specific fear(s) worrying the patient, which is often elicited only by direct questioning. Rheumatology training programmes should specifically address both these issues.

Eleanor Grogan senior house officer

Andrew Frank consultant physician in rehabilitation medicine

Andrew Keat consultant rheumatologist

andrew@franka.demon.co.uk

Northwick Park Hospital, Harrow, Middlesex HA1 3UJ

1 Donovan J, Blake D. Qualitative study of interpretation of reassurance among patients attending rheumatology clinics: "just a touch of arthritis, doctor?" BMJ 2000;320:541-4. (26 February.)

2 Crombez G, Vlaeyen J, Heuts P, Lysens R. Pain-related fear is more disturbing than pain itself: evidence on the role of pain-related fear in chronic back pain disability Pain 1999;80:329-39.

Main C, Waddell G. Spine Update: Behavioral responses to examination: a reapprisal of the interpretation of "non-organic signs" Spine 1998;23:2367-71.
4 Waddell G, Newton M, Henderson I, Somerville D, Main C. A fear avoidance beliefs questionnaire (FABQ) and the role of fear avoidance beliefs in chronic low back pain and disability. Pain 1993;52:157-68.

5 Frank AO. Low back pain: diagnosis and management. London: Current Medical Literature, 2000 (in press).

\section{Clinical academic medicine}

\section{Academics should be rewarded appropriately}

EDITOR-The Academy of Medical Sciences and the Royal College of Physicians are to be congratulated for tackling the problem of recruitment and retention of clinicians in academic medicine and proposing potential solutions, as outlined by Savill. ${ }^{1}$ Although a clearly defined and secure career structure for talented potential academics should help to reverse the trend away from a research based clinical career, the potential negative effect of a substantially longer period in a training post should not be underestimated. Medicine is a hierarchical discipline in which status and income are related to perceived seniority. If academics are truly valued in British medicine then it is important that this is shown in more than just words.

The academy (www.acmedsci.ac.uk) and the royal college ${ }^{2}$ both propose a defined second phase of training for those few talented individuals who have received competitive intermediate research training awards. Clinician scientists selected by this rigorous peer review process will therefore be of the highest calibre, and this should be reflected in their pay and status. This means that they must, at the very least, maintain parity with their NHS peers. They should enter the consultant pay scale after a period of training equivalent to the minimum that their NHS peers would have to complete to receive a certificate of completion of specialist training in their specialty. That this could be achieved through the "clinical senior lecturers without consultant contract" route is encouraging. The cost of such a scheme would be modest compared with its potential benefits. At the same time, an appropriately distinguished title should be conferred. This should be recognisable by patients and peers alike as a mark of both quality and seniority-for example, senior research physician/surgeon/practitioner. The title clinician scientist falls somewhat short of the mark

Finally, but importantly, specialist advisory committees should take the opportunity to re-evaluate their training programmes in the light of the royal college and the academy's reports to determine whether modifications can or should be made to facilitate recruitment of high calibre academics into their discipline (this is more appropriate for some than for others). Failure to do so will inevitably lead to a loss of professional research leadership, which has already occurred in some disciplines, and ultimately to marginalisation of that discipline in British and world medicine. The specialist advisory committees should look 
to their specialist societies to support them in this endeavour.

Peter L Weissberg BHF professor of cardiovascular medicine

University of Cambridge, Cambridge CB2 2QQ plw@mole.bio.cam.ac.uk

1 Savill J.More in expectation than in hope: a new attitude to training in clinical academic medicine. BMJ 2000 320:630-3. (4 March.)

2 Arthur MJP, Alberti KGMM. Training in academic medicine: a way forward for the new millennium. $J R \mathrm{Coll}$ Physicians Lond 1999;33:359-64

\section{Research dominates thinking on medical schools' funding}

EDITOR-Many medical schools will have recently been assessed for our teaching programmes (the QAA) and are preparing for the assessment of research quality (the RAE) in 2001. For the teaching assessment we will have painted a picture of a school devoted to medical education in all its manifestations and a faculty committed to innovation and excellence in teaching. Next year we will do our best to ensure that everyone with an academic contract with the medical school is made to look as useful as possible for the assessment of research quality.

This schizophrenic approach to academic medicine is unacceptable, and it is not tackled in three excellent articles by Savill, Catto, and Tomlinson. ${ }^{1-3}$ Indeed, there is often an elision in these papers between academe and research, despite assertions about the importance of teaching.

More than two thirds of a medical school's income is related to the school's teaching function; a large amount of the service increment for teaching resource is also paid to the associated university hospital trusts. The resource paid in respect of research quality accounts for about one third of a school's core income, and the corresponding research and development funding from the NHS paid to the trust is likely to be less than the amount of the service increment for teaching. Despite this, the assessment of research quality dominates thinking on funding because the teaching assessment has no funding teeth. Falling ratings on the assessment of research quality can have substantial impacts on medical schools; two schools lost about £2m each after the 1996 assessment. A poor score on the teaching assessment has no direct financial consequences. Research performance is the pre-eminent factor driving progression up the clinical academic ladder, with teaching excellence a long way behind. This is, presumably, not what is meant by teaching being research led. Paradoxically, the public is increasingly concerned that we produce excellent doctors, and is much less persuaded about the value of medical research. ${ }^{4}$

Possible solutions include a teaching funding formula that is sensitive to quality as well as volume, emphasis on the assessment of research impact rather than research income and publications, better coordination and less duplication of research effort, and more frequent, intra-institutional self assessment of both research and teaching, as suggested by Tomlinson and which would lead to less seismic potential shifts in funding. With greater transparency at the interface between university and NHS we believe it is possible to create conditions in which academic medicine-teaching as well as research-would indeed flourish.

Roger Jones Wolfson professor of general practice patricia.taylor@kcl.ac.uk

John Moxham professor of medicine

Department of General Practice and Primary Care, Guy's, King's and St Thomas' School of Medicine, London SE11 5SP

1 Savill J. More in expectation than in hope: a new attitude to training in clinical academic medicine. BMJ 2000; 320;630-3. (4 March.)

Catto G. Interface between university and medical school: the way ahead? BMJ 2000;320;633-6. (4 March.)

Tominon S. The research assesment exercise and medicon

4 Goldbeck-Wood S. Reviving academic medicine in Britain. BMJ 2000;320;591-2. (4 March.)

\section{Surgical trainees face particular} problems

EDITOR-Many of the problems identified by Savill and Catto on reviving clinical academic medicine are accepted, but solution are more difficult. ${ }^{2}$ However, the suggestions for improving academic training with a new career structure are more relevant to the "medical" specialties and do not adequately recognise the additional difficulties in the academic "craft industries"-for example, surgery in general and genera surgery in particular. In addition to the well known generic problems related to academic medicine, such as lack of flexibility, insecurity, financial disincentives, and length of training, there are specific additional problems for surgical trainees:

- The required acquisition of technical skills-"deskilling" can occur when periods longer than two years are taken out of service. This can be exacerbated if the period of clinical training before the time out as a clinician scientist is relatively short. In addition, specialisation means that individuals may well be unable to maintain general emergency skills if academic skills as a clinician scientist can be acquired only through excess absence from clinical rotas. This will result in a considerable extension of the training period for academic surgeons.

- Surgical trainees are put off by unrealistic expectations required by academic interview committees-for example, the need for peer review grants and high quality peer review publications in high impact journals at an early stage in their career.

- As a result of changes in manpower, the number of trainees applying for consultant posts in the specialties of general surgery has reduced, and therefore the "market force" effect is such that fewer individuals apply for onerous and time consuming academic posts.

If recruitment to academic surgery is to be encouraged then a realistic expectation of success is essential, and remuneration consistent with the extra training and responsibility of academic surgeons is a necessity. Medical schools should emphasise clinical and teaching abilities in addition to research potential. Promotion in medical schools should be based on factors other than pure research, especially for clinical academic surgeons.

The importance of clinical and technical skill is as great for academic surgeons as for NHS surgeons, but the additional activity required for academic surgeons should be recognised for what it is-additional training-and appropriate rewards should be made available. It is important that young surgeons who wish to enter a career in academic surgery should no longer be discouraged by poor prospects and financial disincentives.

I Taylor professor of surgery

Department of Surgery, Royal Free and University College Medical School, London W1P 7LD

1 Savill J. More in expectation than in hope: a new attitude to training in clinical academic medicine. BMJ 2000; 320:630-3. (4 March.)

2 Catto GRD. Interface between university and medical school: the way ahead? BMJ 2000;320:633-6. (4 March.)

\section{There are problems for general practice}

EDIToR-None of the excellent papers on academic medicine in the 4 March issue refers directly to academic general practice. ${ }^{1-3}$ We agree that clinical academics are essential to the development of health care and believe that academic general practice is vital for primary health care in the National Health Service of the 21st century. The Mant and Clarke reports (http:// www.doh.gov.uk/ research/documents/rdpc report.pdf) emphasise the importance of primary care research, and the MRC Topic Review has resulted in a second round of substantial funding from the Medical Research Council and Department of Health for primary care research initiatives. ${ }^{45}$ High quality research in primary care is a prerequisite for clinical effectiveness and clinical governance in an evidence based service.

We particularly welcome Savill's "research access" proposal-similar in concept to the successful London academic trainee scheme and to the higher professional training fellowship scheme developed in Scotland: but if the proposed two-phase academic career structure is to be made applicable to academic general practice, some modification will be required in structure and funding. The forthcoming report from the Academy of Medical Sciences on clinical academic careers considers the position of general practice in rather more detail. Savill's article concentrates on clinical academic medicine, but it is important to recognise the increasing multidisciplinarity of research, and the Association of University Departments of General Practice is preparing a report on careers in academic primary care, in which career structures for non-clinical scientists are also considered.

Catto's thought provoking paper may have left readers with the impression that the issue of distinction awards for clinical academic staff has been settled. This is not the case for general practice, and it remains a major disincentive to talented young primary care physicians considering a long 
term academic career. There is also an implication that teaching in the community and general practice is, somehow, taking place separately from the medical school, whereas the academic departments work intensely to integrate and support their NHS general practitioner teachers-within practices and primary care groups.

In Tomlinson's searching analysis of the research assessment exercise, there are important comments about the higher ratings given to molecular science than to clinical and health services research, the need to focus research portfolios in institutions, and the relative lack of participation by the NHS in the 1996 research assessment exercise. These are important points with major implications for the bibliometric indices of the core journals of academic general practice-a young discipline yet one in which the quality of much research stands international comparison.

\section{Roger Jones chairman patricia.taylor@kcl.ac.uk \\ Sean Hilton chairman \\ Association of University Departments of General Practice, London SE11 6SP}

1 Savill J.More in expectation than in hope: a new attitude to training in clinical academic medicine. BMJ 2000, 320;630-3. (4 March.)

2 Catto G. Interface between university and medical school: the way ahead? BMJ 2000;320;633-6. (4 March.)

3 Tomlinson S. The research assessment exercise and medical research. $B M J$ 2000;320;636-9. (4 March.)

NHS Executive. RED in primary care: National Working Group report. London: Department of Health, 1997.

5 Medical Research Council. Primary health care: MRC topic review. London: Medical Research Council, 1997.

\section{Quick fixes for research assessment exercise will not work}

EDitor-Tomlinson challenges those who seek to abandon the research assessment exercise to propose a credible alternative for the accountable allocation of public money. ${ }^{1}$ Goldbeck-Wood quotes a patients' spokesman, Clive Wilkinson, as saying, "The public understands that research is essential; but it needs to be on their terms-not on the basis of what is comfortable to academics."

The research assessment exercise's criteria are those by which scientists customarily judge their peers; as Tomlinson observes, they take little account of the impact of medical research on the quality of practice. The alternative to the exercise is to place health related research and development at the heart of NHS change management.

Applied medical research is not "science." Its "change promoting paradigm" is directed toward the needs of resource managers (including clinicians). Thus research and development should be commissioned to meet the particular needs of managers and aid real life decision taking.

Programmes of research and development encompassing clinical, economic, humanistic, and implementation issues are needed rather than the current plethora of inconsequential studies. Medical schools should receive their infrastructure funding within these programmes (implying transfer of some Higher Education Funding Council money to the NHS). Many programmes will be rolling ones, and continuation of funding should be conditional on researchers having engaged in the concerns of the commissioners.

Once confidence in commissioning has been achieved it will be time to do likewise with the applied research component of Medical Research Council money; direct transfer to the NHS seems best. Finally, the research charities will perceive the strength of commissioning and realise the benefits (for example, the more ready implementation of affordable advances) of collaborating with NHS resource managers.

Accomplishing this may not be easy. But I challenge people to tell me not that it "cannot" be done but why it "should not" be done.

Selwyn St Leger consultant in public health medicine University of Manchester, School of Epidemiology and Health Sciences, Manchester M13 9PT

Selwyn.St.Leger@man.ac.uk

1 Tomlinson S. The research assessment exercise and medical research. BMJ 2000;320:636-9. (4 March.)

Coldbeck-Wood S. Reviving academic medicine in Britain. BMJ 2000;320:591-2. (4 March.)

3 St Leger AS, Walsworth-Bell JP. Change-promoting research St Leger AS, Walsworth-Bell JP. Change-promoting research
for health services. Buckingham: Open University Press,
1999.

\section{Feedback is necessary in strategies to reduce hospital acquired infection}

EdiTor-The National Audit Office's report about hospital acquired infection in England emphasises the role of improved surveillance and involvement of clinicians in control of hospital acquired infection. ${ }^{12}$ The executive summary states that surveillance and feedback to clinicians are central to reducing infection rates and recommends that senior clinicians are encouraged to accept greater ownership for control of hospital acquired infection. This relates strongly to risk management and clinical governance, and the audit office calls for development of the evidence base and dissemination of information on best practice.

We report here our experience of feedback and the involvement of clinicians in reducing the incidence of Clostridium difficile associated diarrhoea, a common form of hospital acquired infection related to overuse of cephalosporins. In July 1995, because of high endemic levels of $C$ difficile associated diarrhoea in our acute elderly care unit, we introduced an enhanced infection control policy: we restricted use of cephalosporins and gave feedback on rates of $C$ difficile associated diarrhoea and use of antibiotics.

This succeeded, ${ }^{3}$ and the policy continued for nearly two years. Rates of $C$ difficile associated diarrhoea fell from 3.83 to 0.91 cases per 100 admissions, and use of cephalosporins fell from 20 to 6 notional seven day courses per 100 admissions (figure).

Feedback was then relaxed because of the absence of the lead clinician, creating what was virtually a multiple crossover study of its effect. Rates of $C$ difficile associated diarrhoea and use of cephalosporins both rose until the end of 1998, when clinicians became aware of the rising levels of the diarrhoea (2.66 per 100 admissions) and started to re-enforce the antibiotic policy. The incidence of new cases of methicillin resistant Staphylococcus aureus had also been fed back to clinicians and, when feedback was relaxed, rose from 2.93 to 4.01 per 100 admissions.

These data, collected for 7423 consecutive admissions over four years, show the value of feedback in reducing both $C$ difficile associated diarrhoea and use of antibiotics; they support the National Audit Office's rec-

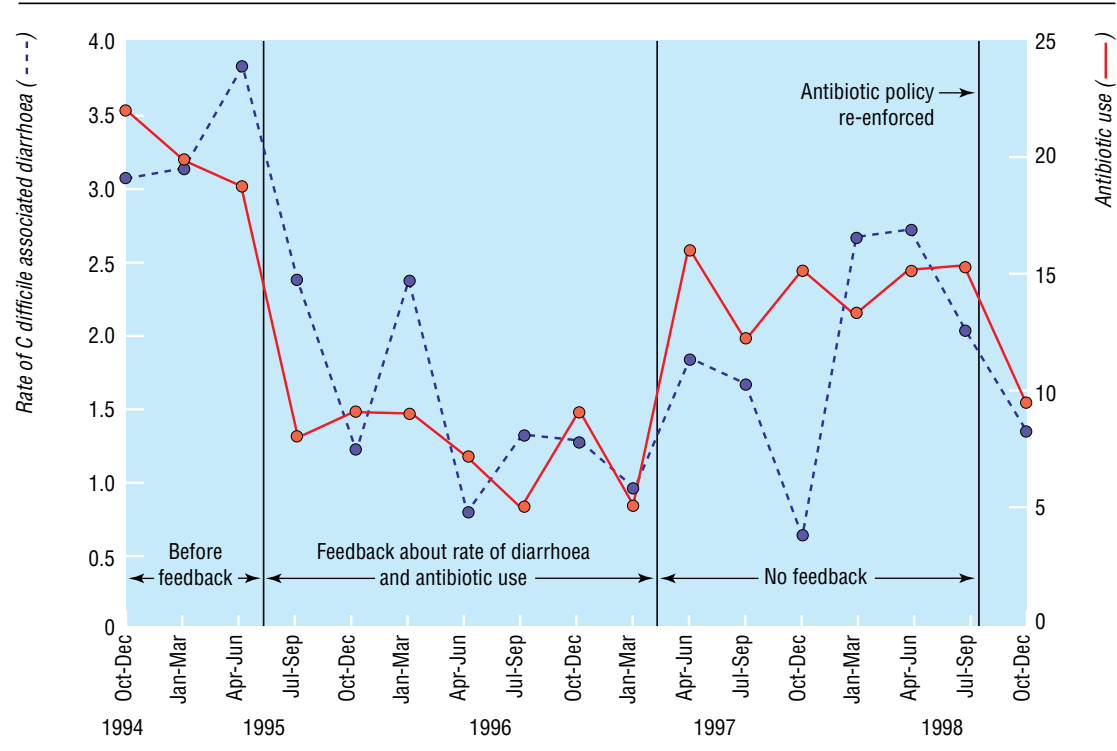

Quarterly rate of $C$ difficile associated diarrhoea and use of antibiotics (notional seven-day courses of cephalosporin) 
ommendations regarding surveillance and the involvement of clinicians in the control of hospital acquired infection.

This multiple crossover study is the only one to examine and show the effectiveness of feedback in reducing $C$ difficile associated diarrhoea. Feedback reduces both postsurgical infection ${ }^{4}$ and infection with methicillin resistant $S$ aureus, ${ }^{5}$ but we believe that success is more likely if initiatives are led by key clinicians. Ownership of strategies tends to result in more care in their use.

Sheldon Stone senior lecturer

Academic Department of Geriatric Medicine, Royal Free and University College Medical School, London NW3 2PF

s.stone@rfc.ucl.ac.uk

Christopher Kibbler consultant, department of medical microbiology

Anne How infection control nurse, department of medical microbiology

Anita Balestrini principal pharmacist, department of pharmacy

Royal Free NHS Trust (Hampstead), London NW3 2OG

1 Kmietowicz Z. Hospital infection rates in England out of control. BMJ 2000;320:534. (26 February.)

2 National Audit Office. The management and control of hospital acquired infection in acute NHS trusts in England. London: tal acquired infection in acute NHS trusts in

3 Stone SP, Beric V, Quick A, Balestrini AA, Kibbler CC. The effect of an enhanced infection control policy on the incidence of Clostridium difficile infection and methicillinresistant Staphylococcus aureus colonisation in acute elderly medical patients. Age Ageing 1998;27:561-8.

4 Haley RW, Culver DH, White JW, Morgan WM, Emori TG, Munn VP, et al. The efficacy of infection surveillance and control programmes in preventing nosocomial infection in YS hospitals. Am J Epidemiol 1985;121:182-205.

5 Nettleman MD, Trilla A, Frederickson M, Pfaller M. Assigning responsibility: using feedback to achieve sustained control of methicilin-resistant Staphylococcus aur. J Med 1991;91(3B):228-32S.

\section{Police surgeons are important part of criminal justice system}

EDITOR-Clinical forensic medicine is one of the most dynamic and rapidly advancing specialties, but the article in Career Focus missed an opportunity to show just how the work of a police surgeon has changed in recent years.

In contrast to the views expressed, the assessment of drink-drivers is now a minor component of the work. Much more of the doctor's time is spent assessing substance misusers, mentally ill people, injured prisoners, and people with pre-existing morbidity to determine their fitness for detention; their fitness to be released, charged, or transferred; their fitness to be interviewed by the police; and whether an appropriate adult is required. ${ }^{2}$ The examination of both adults and children who complain of serious sexual assaults is also an essential part of the role.

Although most police surgeons are general practitioners who work as police surgeons part time, increasing numbers work as specialists in clinical forensic medicine. Pal is mistaken with respect to the contractual arrangements in the Metropolitan Police area, where the doctors are still self employed. Regardless of the background of the doctor, the importance of independence and impartiality cannot be underestimated.
All consultations by police surgeons have a potential forensic element, so all police surgeons need to be properly trained and forensically aware. Excellent basic training courses have been run for several years in London and Durham; more advanced courses by the Forensic Academic Group in the North in Manchester and the DMJ Study Club in London prepare doctors to sit the diploma in medical jurisprudence.

The Association of Police Surgeons and, in particular, its education and research subcommittee have been at the forefront in developing educational and training materials for use by doctors, such as the practical induction programme for newly appointed police surgeons ${ }^{3}$ and the police custody officer training package. ${ }^{4}$ The association also holds two conferences each year, which provide forums for doctors to meet and learn. The Journal of Clinical Forensic Medicine, which publishes original work as well as definitive reviews on the clinical aspects of forensic medical work, has also been an exciting development in recent years.

The art of clinical forensic medicine is based on knowledge and experience. It is essential that, within the ethos of best value, we do not lose sight of the importance of having appropriately trained and supported doctors in the criminal justice system.

Margaret M Stark chair, education and research subcommittee, Association of Police Surgeons Association of Police Surgeons, 18A Mount Parade, Harrogate, North Yorkshire HG1 1BX

stark@cheam.demon.co.uk

1 Pal R. Police surgeon [career focus]. BMJ 2000;320(classified section $26 \mathrm{Feb}$ ):2-3. (classified.bmj.com/careerfocus/ fied section

2 Howitt J, Stark MM. The role of the independent forensic physician Harrogate: Education and Research Subcommittee of the Association of Police Surgeons, 1996 (revised 1999).

3 Evans V. Training diary for newly appointed police surgeons. Harrogate: Education and Research Subcommittee of the Association of Police Surgeons, 1997

4 Wall I, Stark MM. Custody officer training outline. Harrogate: Education and Research Subcommittee of the Association of Police Surgeons, 1999

\section{Infant feeding and HIV study does not support Minerva's view}

EDITOR-Minerva's report of the study by Nduati et al into HIV and infant feeding quotes figures for babies alive and free of infection with HIV-1 at two years. ${ }^{1}$ One striking finding was the lack of overall difference in infant mortality between the two trial arms despite a higher level of HIV transmission in the breast fed arm, implying a trade off between mortality related to HIV and artificial feeding.

A review of the risks of not breast feeding found that infants not breast fed have a sixfold greater risk of dying from infectious diseases in the first two months of life than those breast fed, and that higher levels of protection are seen among less educated women. ${ }^{2}$

Nduati et al defined compliance with the breast feeding arm as meaning any breast feeding. In Nairobi customary practice is for breast fed babies to receive supplemental water, etc. In South Africa, Coutsoudis et al found that infants exclusively fed exclusively formula and those exclusively breast fed had similar rates of early HIV transmission. ${ }^{3}$ Infants who received breast milk and water, teas, and semisolid foods had the highest rates of transmission, similar to those found in Nairobi.

Only $70 \%$ of women in Nduati at al's formula feeding arm complied with the protocol of giving only formula and no breast milk. This implies that interventions to get women to avoid breast feeding in such a cultural setting might increase levels of mixed feeding.

Nduati et al assume that HIV secreted in breast milk can infect the infant and that rates of infection above the exclusively formula fed rate are solely a result of virus in breast milk. Coutsoudis et al point out, however, that ingestion of contaminated water, fluids, and food may lead to gut mucosal injury and disruption of immune barriers, and that HIV-1 is less likely to penetrate intact and healthy gastrointestinal mucosa than damaged mucosa. They also suggest that virus acquired during delivery could have been neutralised by immune factors present in breast milk but not in formula feeds.

Minerva concludes that only complete avoidance of breast feeding will reduce the risk of HIV transfer to babies. Until research is carried out observing the effects of exclusive breastfeeding from birth, there are no adequate data to support this conclusion Exclusive breast feeding is the biological norm. ${ }^{4}$ We are disturbed that so few studies pay adequate attention to it and are surprised at the way Nduati et al, de Cock et $\mathrm{al},{ }^{5}$ and the $B M J$ have ignored it.

Magda Sachs breastfeeding supporter sachsdavis@clara.net

Phyll Buchanan breastfeeding supporter Mary Broadfoot breastfeeding supporter Breastfeeding Network, Paisley, PA2 8YB

Ted Greiner research adviser, nutrition International Maternal and Child Health Unit, Uppsala University, Uppsala, SE-75185, Sweden Competing interests: None declared.

1 Minerva. BMJ 2000;320:724. (11 March.) (Report on Nduati R, John G, Mbori-Ngacha D, Richardson B, Overbaugh J, Mwatha A, et al. Effect of breastfeeding and formul feeding on transmission of HIV-1

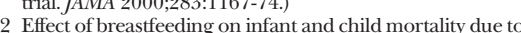
Effect of breastfeeding on infant and child mortality due to infectious diseases in less developed countries: a pool analysis. WHO Collaborative Study Team on the Role of Breastfeeding on the Prevention of Infant Mortality. Lancet 2000;355:451-5

3 Coutsoudis A, Pillay K, Spooner E, Kuhn L, Coovadia HM. Influence of infant-feeding patterns on early mother-tochild transmission of HIV-1 in Durban, south Africa: a prospective cohort study. Lancet 1999;354:471-6.

4 Latham M. Breast feeding reduces morbidity. BMJ 1999:318:1303-4.

5 De Cock K, Fowler M, Mercier E, de Vincenzi I, Saba J, Hoff E, et al. Prevention for mother-to-child HIV transmission in resource-poor countries: translating research into policy and practice. JAMA 2000;283:1175-82.

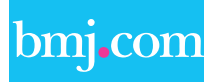

\section{Rapid responses}

Correspondence submitted electronically

is available on our website 